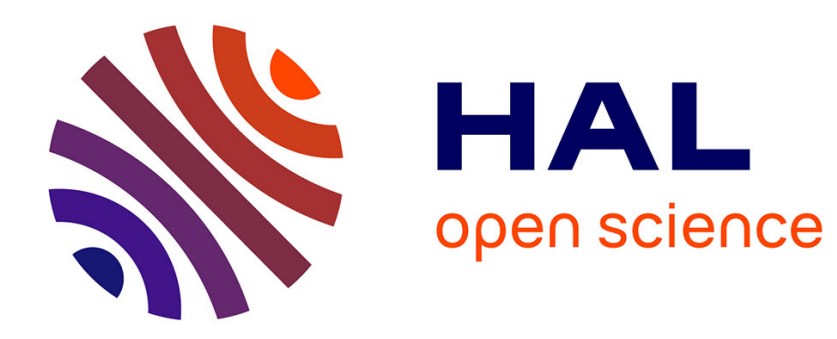

\title{
Linearization of polycrystalline film gauge factors
}

\author{
C.R. Pichard, C.R. Tellier
}

\section{To cite this version:}

C.R. Pichard, C.R. Tellier. Linearization of polycrystalline film gauge factors. Revue de Physique Appliquée, 1979, 14 (8), pp.743-747. 10.1051/rphysap:01979001408074300 . jpa-00244655

\section{HAL Id: jpa-00244655 https://hal.science/jpa-00244655}

Submitted on 1 Jan 1979

HAL is a multi-disciplinary open access archive for the deposit and dissemination of scientific research documents, whether they are published or not. The documents may come from teaching and research institutions in France or abroad, or from public or private research centers.
L'archive ouverte pluridisciplinaire $\mathbf{H A L}$, est destinée au dépôt et à la diffusion de documents scientifiques de niveau recherche, publiés ou non, émanant des établissements d'enseignement et de recherche français ou étrangers, des laboratoires publics ou privés. 


\title{
Linearization of polycrystalline film gauge factors
}

\author{
C. R. Pichard and C. R. Tellier \\ Laboratoire d'Electronique, Université de Nancy I, C.O. 140, 54037 Nancy Cedex, France
}

(Reçu le 30 novembre 1978, révisé le 4 mai 1979, accepté le 8 mai 1979)

\begin{abstract}
Résumé. - Une équation linéaire est proposée pour décrire la dépendance, en fonction de l'épaisseur, du facteur de jauge $\gamma_{F}$, d'un film polycristallin. Finalement la variation théorique de $\gamma_{F}$ est représentée par une équation générale dont la forme est similaire à celle correspondant aux équations linéarisées, préalablement obtenues pour l'étude de la résistivité de films polycristallins et de leur T.C.R. Des comparaisons des valeurs exactes et approchées montrent une déviation inférieure à $10 \%$ sur des domaines étendus du coefficient de diffusion spéculaire $p$, de la distance moyenne entre les joints de grains $a_{\mathrm{g}}$, et du rapport $k$ de l'épaisseur du film au libre parcours moyen.
\end{abstract}

\begin{abstract}
A linearized equation is proposed to describe the thickness dependence of the polycrystalline film gauge factor $\gamma_{F}$. Finally the theoretical variation of $\gamma_{F}$ is represented by a general equation whose form is similar to those related to linearized equations previously derived for analyzing polycrystalline film resistivity and T.C.R. Comparisons of exact and approximate values indicate a deviation less than $10 \%$ over large ranges of the surface scattering specularity parameter, $p$, the average random distance between grain boundaries, $a_{\mathrm{g}}$, and the ratio, $k$, of the film thickness to background mean free path.
\end{abstract}

1. Introduction. - In the recent years it has been observed that evaporated [1-4] and sputtered [5-9] thin metal films exhibit a fine grained structure and thus grain-boundary scattering can significantly dominates the electromechanical properties of these films [10-13]. Mayadas and Shatzkes [14] have taken into account the grain boundary scattering and have proposed a conduction model [14] which describes the combined effects of grain-boundary, external surfaces and background scatterings. The electrical resistivity $\rho_{\mathrm{F}}$ of polycrystalline films is related to the resistivity $\rho_{\mathrm{g}}$ of an infinitely thick polycrystalline film by :

$$
\rho_{\mathrm{F}} / \rho_{\mathrm{g}}=\left[1-\frac{A}{f(\alpha)}\right]^{-1}
$$

with :

$$
\begin{aligned}
A=\frac{6}{\pi k}(1-p) \int_{0}^{\pi / 2} \mathrm{~d} \varphi \int_{1}^{\infty} \frac{\cos ^{2} \varphi}{H^{2}(t, \varphi)}\left(\frac{1}{t^{3}}-\frac{1}{t^{5}}\right) \times \\
\quad \times \frac{1-\exp \{-k t H(t, \varphi)\}}{1-p \exp \{-k t H(t, \varphi)\}} \mathrm{d} t \\
H(t, \varphi)=1+\alpha \cdot(\cos \varphi)^{-1} \cdot\left(1-1 / t^{2}\right)^{-1 / 2}
\end{aligned}
$$

where $\rho_{0}$ is the bulk resistivity, $k$ is the reduced thickness $a / l_{0}$ and $p$ the specularity parameter. $\alpha$ is related to the bulk mean free path $(m f p) l_{0}$, the average random distance between scattering planes which is assumed equal to the average grain diameter, $a_{\mathrm{g}}$ in the M-S model and the grain-boundary reflection coefficient $r$ by :

$$
\alpha=\frac{l_{0}}{a_{\mathrm{g}}} \frac{r}{1-r} .
$$

Tellier and Tosser [10] have developed a mathematical model for the longitudinal and transverse strain coefficient of resistance in thin metallic polycrystalline films.

The longitudinal and transverse strain coefficient of resistivity, $\gamma_{\mathrm{FL}}$ and $\gamma_{\mathrm{FT}}$, can be defined by the equations :

$$
\begin{aligned}
& \gamma_{\mathrm{FL}}=\frac{\mathrm{d} \ln \rho_{\mathrm{F}}}{\left(\frac{\mathrm{d} L}{L}\right)} \\
& \gamma_{\mathrm{FT}}=\frac{\mathrm{d} \ln \rho_{\mathrm{F}}}{\left(\frac{\mathrm{d} w}{w}\right)}
\end{aligned}
$$

and their expressions in the M-S model can be deduced from the previously published results [10]. 
It yields :

$$
\begin{aligned}
& \gamma_{\mathrm{FL}}=(\eta+1)+[f(\alpha)-A]^{-1} \cdot\left\{X(\eta+1)+Y\left(-1-\mu \frac{\left(1-\mu_{\mathrm{s}}\right)}{1-\mu}\right)\right\} \\
& \gamma_{\mathrm{FT}}=(\eta+1)+[f(\alpha)-A]^{-1} \cdot\left\{X\left(\eta-\mu_{\mathrm{s}}\right)+Y\left(\mu_{\mathrm{s}}-\mu \frac{\left(1-\mu_{\mathrm{s}}\right)}{1-\mu}\right)\right\}
\end{aligned}
$$

where :

$$
\begin{aligned}
X & =g(\alpha)-A+B+C \\
Y & =D-A \\
g(\alpha) & =\alpha \frac{\mathrm{d} f(\alpha)}{\mathrm{d} \alpha} .
\end{aligned}
$$

$A$ is defined by eq. (2)

$$
\begin{aligned}
& B=\frac{6}{\pi}(1-p)^{2} \int_{0}^{\pi / 2} \mathrm{~d} \varphi \int_{1}^{\infty} \frac{\cos ^{2} \varphi}{H^{2}(t, \varphi)}\left(\frac{1}{t^{2}}-\frac{1}{t^{4}}\right) \frac{\exp \{-k t H(t, \varphi)\}}{[1-p \exp \{-k t H(t, \varphi)\}]^{2}} \mathrm{~d} t \\
& C=\frac{12 \alpha}{\pi k}(1-p) \int_{0}^{\pi / 2} \mathrm{~d} \varphi \int_{1}^{\infty} \frac{\cos \varphi}{H^{3}(t, \varphi)}\left(\frac{1}{t^{2}}-\frac{1}{t^{4}}\right) \frac{1}{\left(t^{2}-1\right)^{1 / 2}} \frac{1-\exp \{-k t H(t, \varphi)\}}{1-p \exp \{-k t H(t, \varphi)\}} \mathrm{d} t \\
& D=\frac{6}{\pi}(1-p)^{2} \int_{0}^{\pi / 2} \mathrm{~d} \varphi \int_{1}^{\infty} \frac{\cos ^{2} \varphi}{H(t, \varphi)}\left(\frac{1}{t^{2}}-\frac{1}{t^{4}}\right) \frac{\exp \{-k t H(t, \varphi)\}}{[1-p \exp \{-k t H(t, \varphi)\}]^{2}} \mathrm{~d} t
\end{aligned}
$$

Unfortunately the strain coefficient $\gamma_{\mathrm{FL}}$ and $\gamma_{\mathrm{FT}}$ cannot be evaluated analytically and theoretical results related to polycrystalline films have been computed [15]. However this method is complicated and we have studied analytical expressions of the gauge factors which allow a convenient description of the $\alpha, p$ and $k$ dependence of strain coefficients.

\section{Approximate expressions for the gauge factors} of polycrystalline films. -2.1 THE $X$. $[f(\alpha)-A]^{-1}$ FUNCTION. - We have previously shown that the exact expression of the temperature coefficient of resistance (T.C.R.) of polycrystalline films is given by [16] :

$$
\beta_{\mathrm{F}} / \beta_{\mathrm{g}}=\left[1+\frac{g(\alpha)}{f(\alpha)}\right]^{-1} \cdot\left[1+\frac{X}{f(\alpha)-A}\right]
$$

where $\beta_{\mathrm{g}}$ is the T.C.R. of an infinitely thick polycrystalline film. It can be approximate with good agreement by a relation in the form [17] :

$$
k \cdot \beta_{\mathrm{F}} / \beta_{\mathrm{g}} \simeq k-(1-p) \cdot H(\alpha) .
$$

Values of the function $H(\alpha)$ have been previously given [18].

Then by defining for convenience :

$$
m(\alpha)=1+g(\alpha) / f(\alpha)
$$

we may deduce from equation (13) :

$$
k \cdot \frac{X}{f(\alpha)-A} \approx k[m(\alpha)-1]-(1-p) . H(\alpha) \cdot m(\alpha) .
$$

2.2 The $Y \cdot[f(\alpha)-A]^{-1}$ FUnCTION. - Figure 1 shows that the following relation :

$$
\ln \left(-Y^{*}\right) \sim \ln k^{-1}
$$

with :

$$
Y^{*}=Y \cdot[f(\alpha)-A]^{-1}
$$

is satisfied in large $\alpha, p$ and $k$ ranges. Hence for given values $\alpha_{0}$ and $p_{0}$ of the physical parameters $\alpha$ and $p$ :

$$
Y^{*}\left(k, \alpha_{0}, p_{0}\right) \approx-k^{-1} \cdot V\left(\alpha_{0}, p_{0}\right)
$$

where $V\left(\alpha_{0}, p_{0}\right)$ is the slope of linear part of $\ln Y^{*}$, $\ln k^{-1}$ curves.

Further since we may verify (Fig. 1) that :

$Y^{*}\left(k, \alpha_{0}, 0\right)=2 Y^{*}\left(k, \alpha_{0}, 0.5\right)=1.333 Y^{*}\left(k, \alpha_{0}, 0.25\right)$, equation (18) leads to :

$$
Y^{*}\left(k, \alpha_{0}, p_{0}\right) \approx-\left(1-p_{0}\right) k^{-1} \cdot U\left(\alpha_{0}\right) .
$$

Finally we obtain :

$$
k . Y \cdot[f(\alpha)-A]^{-1}=-(1-p) \cdot U(\alpha) .
$$

The values of the $U(\alpha)$ function are given in table I. 


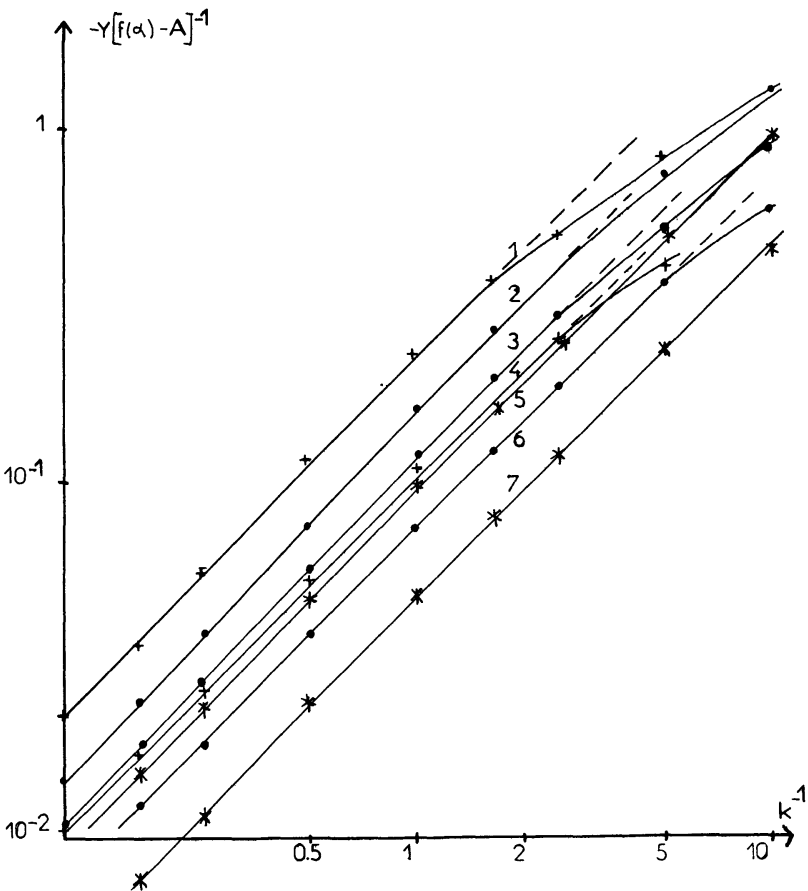

Fig. 1. $--Y \cdot[f(\alpha)-A]^{-1}$ versus $k^{-1}$ in log scales

$$
\begin{array}{ll}
1: \alpha=0.5 & p=0 \\
2: \alpha=1 & p=0 \\
3: \alpha=1 & p=0.25 \\
4: \alpha=0.5 & p=0.5 \\
5: \alpha=2 & p=0 \\
6: \alpha=1 & p=0.5 \\
7: \alpha=2 & p=0.5 .
\end{array}
$$

Table I.

\begin{tabular}{c|lllllll}
$\alpha$ & 0 & 0.25 & 0.5 & 0.75 & 1 & 2 & 5 \\
\hline$U(\alpha)$ & 0.400 & 0.260 & 0.200 & 0.170 & 0.145 & 0.095 & 0.045
\end{tabular}

It would be noted that the corresponding linear plot of $U^{-1}(\alpha)$ against $\alpha$ (Fig. 2) allows us to determine $U^{-1}(\alpha)$ graphically with a sufficient accuracy $(2 \%)$.

The difference between the exact values and those deduced from equation (20) is less than $10 \%$ for $k$ between 0.6 and 10 with $0.25 \leqslant \alpha \leqslant 5$ and $0 \leqslant p \leqslant 0.5$

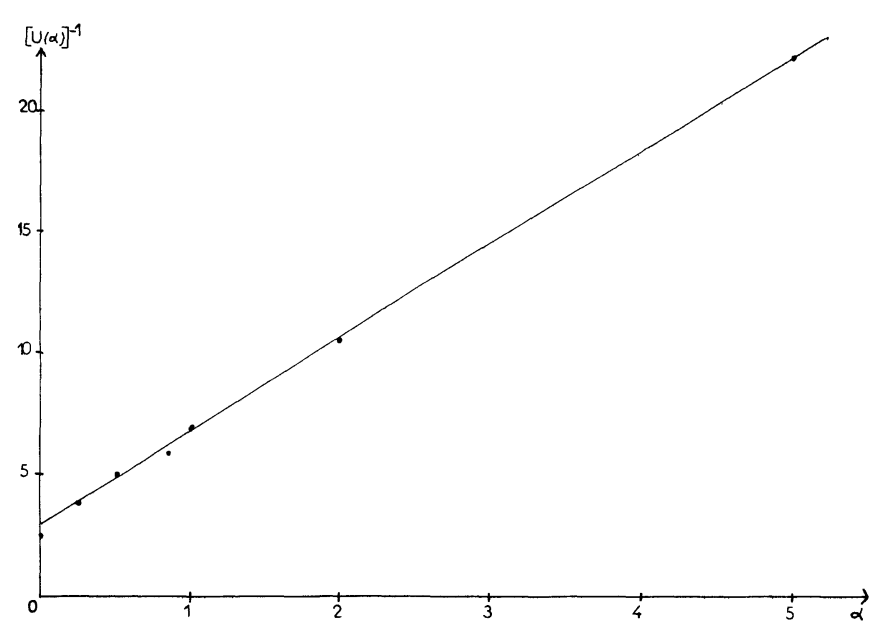

Fig. 2. $-[U(\alpha)]^{-1}$ plotted against $\alpha$.

Table II. - Comparison of the exact and approximate values of the function $-Y \cdot[f(\alpha)-A]^{-1}$.

\begin{tabular}{ccccccccc}
$k$ & \multicolumn{3}{c}{ Exact values (eqs. (1) and (9)) } & \multicolumn{3}{c}{ Approximate values (eq. (20)) } \\
$p=0$ & $\alpha=0.25$ & $\alpha=0.5$ & $\alpha=1$ & $\alpha=2$ & $\alpha=0.25$ & $\alpha=0.5$ & $\alpha=1$ & $\alpha=2$ \\
- & - & - & - & - & - & - & - & - \\
0.06 & 1.6642 & 1.8804 & 1.8311 & 1.4866 & 4.3333 & 3.333 & 2.4167 & 1.5833 \\
0.1 & 1.2261 & 1.3258 & 1.2432 & 0.9716 & 2.60 & 2.00 & 1.45 & 0.950 \\
0.2 & 0.8223 & 0.8278 & 0.7245 & 0.5264 & 1.30 & 1.00 & 0.725 & 0.475 \\
0.4 & 0.5433 & 0.5034 & 0.4032 & 0.2674 & 0.65 & 0.500 & 0.3625 & 0.2375 \\
0.6 & 0.4146 & 0.3647 & 0.2759 & 0.1744 & 0.4333 & 0.3333 & 0.2417 & 0.1583 \\
1 & 0.2798 & 0.2308 & 0.1641 & 0.1003 & 0.260 & 0.200 & 0.1583 & 0.095 \\
2 & 0.1462 & 0.1137 & 0.0780 & 0.0479 & 0.130 & 0.100 & 0.0725 & 0.0475 \\
4 & 0.0704 & 0.0543 & 0.0376 & 0.0234 & 0.065 & 0.050 & 0.03625 & 0.0238 \\
6 & 0.0459 & 0.0356 & 0.0247 & 0.0155 & 0.0433 & 0.0333 & 0.0242 & 0.0158 \\
10 & 0.0270 & 0.0210 & 0.0147 & 0.0092 & 0.26 & 0.0200 & 0.0145 & 0.0095 \\
$p=0.5$ & & & & & & & & \\
- & & & & & & & & \\
0.06 & 0.9188 & 0.9619 & 0.8838 & 0.6867 & 2.1667 & 1.6667 & 1.208 & 0.7917 \\
0.1 & 0.6877 & 0.6855 & 0.6016 & 0.4627 & 1.30 & 1.00 & 0.725 & 0.475 \\
0.2 & 0.4543 & 0.4225 & 0.3458 & 0.240 & 0.650 & 0.50 & 0.3625 & 0.2375 \\
0.4 & 0.2839 & 0.2468 & 0.1883 & 0.120 & 0.325 & 0.250 & 0.1813 & 0.1188 \\
0.6 & 0.2080 & 0.1744 & 0.1281 & 0.0813 & 0.2167 & 0.1667 & 0.1208 & 0.0792 \\
1 & 0.1345 & 0.1085 & 0.0769 & 0.0478 & 0.130 & 0.100 & 0.0725 & 0.0475 \\
2 & 0.0692 & 0.0540 & 0.0375 & 0.0234 & 0.065 & 0.050 & 0.0363 & 0.0238 \\
4 & 0.0340 & 0.0264 & 0.0184 & 0.0116 & 0.0325 & 0.0250 & 0.0181 & 0.0119 \\
6 & 0.0225 & 0.0175 & 0.0122 & 0.0077 & 0.0217 & 0.0167 & 0.0121 & 0.0079 \\
10 & 0.0133 & 0.0104 & 0.0073 & 0.0046 & 0.0130 & 0.0100 & 0.0073 & 0.0048
\end{tabular}


(table II). It may be noted that when the electronic scattering on external surfaces on the film is completely specular, i.e. when $p=1$, the conduction equations are those related to infinitely thick film; hence, there is no deviation between exact and approximate equations. It can be seen that the greater the values of $\alpha$ the larger the range of applicability of the approximate form becomes. In the case of diffuse scattering a deviation of less than $10 \%$ is obtained for $k$ between 0.6 and 10 with $\alpha$ equal to 0.25 and for $k$ between 0.02 and 10 with $\alpha=5$.

2.3 ANALYTICAL EXPRESSIONS FOR THE THIN POLYCRYSTALLINE GAUGE FACTORS. - Introducing equations (20) and (16) into equations (6) and (7) the gauge factors may be written, using equation (15) :

$$
\begin{aligned}
& k \cdot \gamma_{\mathrm{FL}} \approx m(\alpha) \cdot[\eta+1] \cdot k-(1-p) \times \\
& \times\left\{(\eta+1) \cdot H(\alpha) \cdot m(\alpha)-\left(1+\mu^{\prime}\right) U(\alpha)\right\} \\
& k \cdot \gamma_{\mathrm{FT}} \approx k\left\{(\eta+1)+\frac{g(\alpha)}{f(\alpha)}\left(\eta-\mu_{\mathrm{s}}\right)\right\}- \\
&-(1-p)\left\{\left(\eta-\mu_{\mathrm{s}}\right) \cdot H(\alpha) \cdot m(\alpha)+\left(\mu_{\mathrm{s}}-\mu^{\prime}\right) U(\alpha)\right\}
\end{aligned}
$$

with :

$$
\mu^{\prime}=\mu \frac{\left(1-\mu_{\mathrm{s}}\right)}{1-\mu} .
$$

Exact and approximate values of the strain coefficients are given in table III; it shows that a fair agreement is obtained when $k$ takes values above 0.6 .
Accordingly, a plot of $k \gamma_{\mathrm{FL}}$ versus $k$ (for example) should yield a straight line with the intercept as :

$(1-p)\left\{(\eta+1) \cdot H(\alpha) \cdot m(\alpha)-\left(1+\mu^{\prime}\right) U(\alpha)\right\}$

and the slope as :

$$
m(\alpha) \cdot\{\eta+1\}
$$

In the one hand we observe (equations (21), (22) and (23)) that, as expected, values of the slope are equal to the values $\gamma_{\mathrm{gL}}$ and $\gamma_{\mathrm{gT}}$ of gauge factors related to infinitely thick polycrystalline films [10]. Consequently it follows that the thin polycrystalline film gauge factors $\gamma_{F}$ are given by the general formula :

$$
k \gamma_{\mathrm{F}} / \gamma_{\mathrm{g}} \approx k-(1-p) \cdot F\left(\alpha, \eta, \mu_{\mathrm{s}}, \mu\right) \text {. }
$$

It must be pointed out that the polycrystalline film resistivity $\rho_{\mathrm{F}}$ and T.C.R. $\beta_{\mathrm{F}}$ are given by :

$$
\begin{aligned}
& k \cdot \rho_{\mathrm{F}} / \rho_{\mathrm{g}} \approx k+(1-p) \cdot h(\alpha) \\
& k \cdot \beta_{\mathrm{F}} / \beta_{\mathrm{g}} \approx k-(1-p) \cdot H(\alpha)
\end{aligned}
$$

according to previously published works $[17,19]$.

Comparison of equations $((25),(26)$ and (27)) suggest that all the transport properties of polycrystalline films may be described with fair agreement by approximate expressions deduced by considering $\alpha$ and $p$ as separated variables.

On the other hand, suppose that simultaneous

Table III. - Comparison of the exact and approximate values of $\gamma_{\mathrm{FL}}$ and $\gamma_{\mathrm{FT}}$.

\begin{tabular}{cccc}
$k$ & \multicolumn{3}{c}{ Exact values [20] } \\
$p=0$ & $\alpha=0.5$ & $\alpha=1$ & $\alpha=2$ \\
- & $\overline{0}$ & -1 & - \\
0.6 & 2.4532 & 2.2316 & 1.7293 \\
1 & 1.4268 & 1.1131 & 0.7616 \\
6 & 1.3546 & 1.0300 & 0.6923 \\
10 & 1.2956 & 0.9459 & 0.6164 \\
$p=0.5$ & 1.2922 & 0.9401 & 0.6109 \\
- & & & \\
0.1 & & & \\
0.6 & 1.7344 & 1.4622 & 1.0763 \\
1 & 1.3413 & 1.0109 & 0.6759 \\
6 & 1.3157 & 0.9769 & 0.6454 \\
10 & 1.2914 & 0.9387 & 0.6095 \\
& 1.2897 & 0.9359 & 0.6068
\end{tabular}

$p=0.25$
-
0.1
0.6
1
6
10

Exact values [20]

$$
\alpha=0.5
$$

$$
\begin{gathered}
\alpha=1 \\
-6454 \\
1.6133 \\
1.6218 \\
1.6371 \\
1.6382
\end{gathered}
$$

$\gamma_{\mathrm{FL}}$

\begin{tabular}{ccc}
\multicolumn{3}{c}{ Approximate values (eq. (21)) } \\
$\alpha=0.5$ & $\alpha=1$ & $\alpha=2$ \\
- & - & - \\
1.6327 & 1.7444 & 1.4533 \\
1.3449 & 1.0671 & 0.7444 \\
1.3219 & 1.0129 & 0.6877 \\
1.2931 & 0.9452 & 0.6168 \\
1.2908 & 0.9398 & 0.6111
\end{tabular}

$\begin{array}{lll}1.4600 & 1.3380 & 1.0279 \\ 1.3161 & 0.9994 & 0.6735 \\ 1.3046 & 0.9723 & 0.6451 \\ 1.2902 & 0.9384 & 0.6097 \\ 1.2891 & 0.9357 & 0.6069\end{array}$

$\gamma_{F T}$

$\alpha=2$
-
1.5474
1.4995
1.5003
1.5019
1.5021

Approximate values (eq. (22))

$\begin{array}{ccc}\alpha=0.5 & \alpha=1 & \alpha=2 \\ - & - & - \\ 1.2956 & 1.4589 & 1.4904 \\ 1.7067 & 1.6098 & 1.4991 \\ 1.7395 & 1.6219 & 1.5004 \\ 1.7807 & 1.6370 & 1.5019 \\ 1.7839 & 1.6382 & 1.5021\end{array}$


experimental study of the grain-boundary and size effects in electrical resistivity $\rho_{\mathrm{F}}$ and gauge factor $\gamma_{\mathrm{F}}$ has been undertaken ; values of the physical parameter $\alpha$ and specularity coefficient $p$ are easily deduced $[10,18,19]$ from resistivity data and the corresponding values of $m(\alpha)$ and $U(\alpha)$ functions may thus be obtained. For a given value of $\mu_{\mathrm{s}}$, data on the gauge factor allow us to calculate experimental values of the strain coefficient $\eta$ and Poisson ratio $\mu$ of bulk material by using equation (21) or (22). Comparison of these values with theoretical values of $\mu$ and $\eta$ (as given in literature) will then furnish further information on the conduction mechanisms occurring in the films, especially on the influence (on transport properties) of other structural defects such as point defects or impurities frozen in the thin polycrystalline film during the nucleation and growth process.

3. Conclusion. - Variations in the gauge factor of polycrystalline films with thickness may be described with a good agreement by an approximate equation deduced from the Mayadas-Shatzkes conduction model by considering $\alpha$ and $p$ as separated variables. The physical parameters $\eta$ and $\mu$ can then be easily extracted with reasonable accuracy from experimental plots of $\gamma_{\mathrm{F}} \cdot k$ against $k$ for polycrystalline films by using these linearized approximate expression.

\section{References}

[1] Chopra, K. L., Thin Film Phenomena (McGraw-Hill, New York) 1969

[2] Neugebauer, C. A., Phys. Thin Films 2 (1964) 1.

[3] Admon, V., Bar-Or, A. and Treves, D., J. Appl. Phys. 44 (1973) 2300

[4] Golmayo, D. and Sacedon, I. L., Thin Solid Films 35 (1976) 137.

[5] Laville Saint-Martin, B., Thin Solid Films 6 (1970) 359.

[6] Tellier, C. and Tosser, A., Thin Solid Films 37 (1976) 207.

[7] Tellier, C., Vacuum (to be published).

[8] Toombs, P. A. B. and Bennett, P., J. Appl. Phys. 39 (1968) 2948.

[9] Cornely, R. H. and Ali, T. A., J. Appl. Phys. 49 (1978) 4094.

[10] Tellier, C. R. and Tosser, A. J., Electrocomp. Sci. Technol. 4 (1977) 9.

[11] Verma, B. S., Malmotra, G. L. and Sharma, S. K., Thin Solid Films 6 (1970) R9.
[12] Awatar Singh, Thin Solid Films 21 (1974) 225.

[13] Tellier, C. R. and Tosser, A. J., Thin Solid Films 52 (1978) 53.

[14] Mayadas, A. F. and Shatzkes, M., Phys. Rev. B 1 (1970) 1382.

[15] Boutrit, C., Nancy, Private Communication.

[16] Tellier, C. R. and Tosser, A. J., Thin Solid Films 44 (1977) 141.

[17] Tellier, C. R. and Boutrit, C., Thin Solid Films 46 (1977) 307.

[18] Teluier, C. and Tosser, A., Le Vide 189 (1977) 121.

[19] Tellier, C. R. and Tosser, A. J., Thin Solid Films 33 (1976) L19.

[20] Tellier, C. R. and Tosser, A. J., Thin Solid Films 57 (1979). 